\title{
Correlation of Pregnancy-Associated Plasma Protein (PAPP-A) in Serum and Follicular Fluid with Oocyte and Embryo Quality in PCOS and non-PCOS Women Undergoing ICSI Cycle
}

\author{
Zeena Salim Altimimi ${ }^{1}$, Mufeda Ali Jwad ${ }^{1}$, Amal A. Mohammed ${ }^{1}$ \\ ${ }^{1}$ High Institute of Infertility Diagnosis and Assisted Reproductive Technologies, Al Nahrain University, Baghdad, Iraq. \\ zenasaleem90@gmail.com
}

\section{Pregnancy-Associated Plasma Protein (PAPP-A) is a zinc} metalloproteinase in the insulin growth factor system (IGFs) produced by the syncytiotrophoplast region of the placenta. It plays a critical function in the cleavage of IGFBP4. In the ovary IGFs, it regulates follicular and oocyte maturation, and steroidogenesis. While in polycystic ovarian syndrome (PCOS) Hyperinsulinemia and hyperandrogenemia it causes follicular environment changes and early ovulation resulting in lower oocyte and embryo quality in patients and this will decrease the success of pregnancy in women enrolled in the ICSI cycle. The present study aimed to assess the relationship of PAPP-A levels in serum and follicular fluid in women with PCOS and non-PCOS with oocyte and embryo quality in women undergoing ICSI cycle. 45 infertile Iraqi women were enrolled. Women with PCOS had to meet at least two of the three criteria set by the Rotterdam ESHRE/ASRMS criteria, the age of the included women ranged between 20-45 years. In non-PCOS patients, PAPP-A has higher level in serum and follicular fluid but without a statistically significant difference matching with PCOS group. In addition, there was no significant correlation between PAPP-A levels in serum and follicular fluid with oocytes and embryo characteristics. However, PAPP-A levels are higher in serum and follicular fluid in women with positive pregnancy but without significant differences. PAPP-A had no correlation with oocyte and embryo quality.

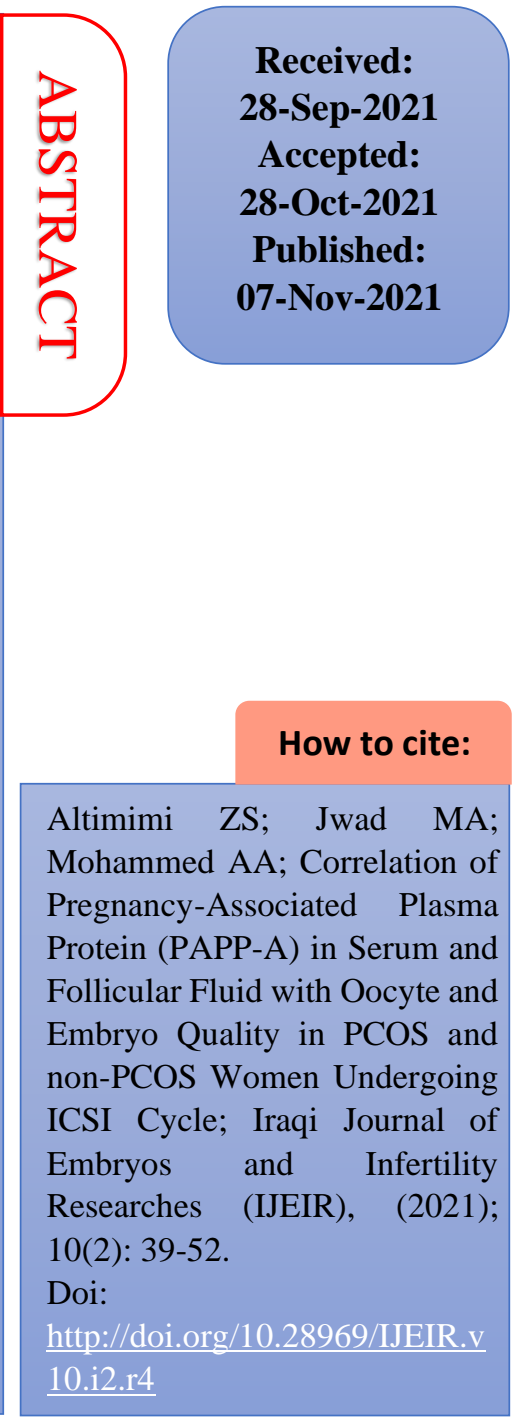

KEYWORDS

Infertility, Polycystic Ovarian Syndrome, Pregnancy-Associated Plasma Protein, Intra Cytoplasmic Sperm Injection, Oocyte and Embryo Characteristics 


\section{Introduction}

Infertility is one of the most frequent health problems in the world, resulting from genetic or pathological diseases, prompting ongoing research and studies in the field of assisted reproductive technology (ART) to find the best treatment options possible (Mongkolchaipak, $S^{[1]}$ ). Despite the efforts of fertility clinics worldwide in the field of ART, there are an estimated $13 \%$ of couples influenced by infertility. Therefore, a successful pregnancy needs high-quality oocytes and embryos (Chen, et al. ${ }^{[2]}$ ). Polycystic Ovarian Syndrome (PCOS) is the most frequent endocrine condition and the predominant cause of female infertility, according to studies conducted around the world (Deshpande and Gupta $\left.{ }^{[3]}\right)$. PCOS, affects 5-15\% of women and result of ovulatory failure (Ecklund and Usadi $\left.{ }^{[4]}\right)$. The clinical expression varies widely but commonly includes oligoanovulation or anovulation, hyperandrogenism (either clinical or biochemical), and the presence of polycystic ovaries on ultrasonography (Fauser, et al. ${ }^{[5]}$ ). In PCOS patient premature granulosa cell luteinization and disruption of the intrafollicular environment are caused by increased ovarian hyperandrogenism and hyperinsulinemia, resulting in poor follicular development and oocyte maturation (Ecklund and Usadi ${ }^{[4]}$ ). Pregnancy-Associated Plasma Protein A (PAPP-A) is a glycoprotein and a highly selective metalloproteinase that attaches to glycosaminoglycans on the cell surface and associated in the cleavage of IGFBP, specifically IGFBP4,5, resulting in an increase in bioactive IGF. PAPP-A also acts as a growth-promoting enzyme within the tissue, producing bioactive IGF when it comes into contact with IGF receptors ( $\mathbf{O x v i g ,} \mathbf{C}^{[6]}$ ). IGFs are major intraovarian regulators of follicle growth, selection, cellular differentiation, and steroidogenesis, as well as oocyte maturation and cumulus expansion, according to members of the IGF family (Kwintkiewicz and Giudice $\left.{ }^{[7]}\right)$. The proteolytic activity of PAPP-A toward IGFBP-4 was detected in human follicular fluid. The IGF system appears to contribute to the reported resistance to follicle-stimulating hormone (FSH) activity and the persistence of an androgen-dominant environment in the 
arrested follicles in PCOS, a condition characterized by small antral follicle arrest resulting in anovulation (Kwintkiewicz and Giudice $^{[7]}$, Öztürk, et al. $\left.{ }^{[8]}\right)$. This study is going to assess the correlation between PAPPA levels and oocyte and embryo characteristics in serum and follicular fluid of women undergoing Intracytoplasmic Sperm Injection (ICSI) cycle.

\section{Materials and Methods}

This study involved 45 infertile females who were enrolled in assisted reproductive technology (ART) programs through undergoing ICSI cycles at the High Institute for Infertility Diagnosis and Assisted Reproductive Technologies, Al Nahrain University, Baghdad, Iraq, during the period from September 2020 to May 2021. All couples were subjected to the basic fertility work-up of the fertility center, which includes case history, physical examination, ovulation detection, assessment of the tubal and uterine cavity, and semen analysis. The morphological evaluation of oocytes retrieved from infertile women and their resulting embryos was performed in the ICSI lab of the High Institute for Infertility Diagnosis and Assisted Reproductive Technologies. While the measurement of PAPP-A in serum and follicular fluid was done using the EnzymeLinked Immunosorbent Assay (ELISA) kit (Shanghai Biological, China). The blood samples were collected by venipuncture from each infertile woman on the both days of oocyte retrieval and embryo transfer. They were then centrifuged for 15 minutes at 1000 g. The serum was removed and stored at $-20^{\circ} \mathrm{C}$ or $-80^{\circ} \mathrm{C}$. The Follicular Fluid (FF) was obtained from the first retrieved follicle to avoid contamination of blood and flushing medium, and collected in a plane tube. It was frozen at $-20^{\circ} \mathrm{C}$ for approximately 20 minutes before being analyzed. The measurement of PAPP-A serum and follicular fluid levels was assessed by the ELISA kit.

\section{Statistical Analysis}

The data were investigated using Statistical Package for Social Sciences (SPSS) version 22.0 and Microsoft office 2007. The descriptive statistics including frequency, mean and standard deviation were measured to 
describe the data. The groups were compared by applying independent sample t-test (unpair t-test between two groups), paired sample ttest (same variable between two periods e.g. pick up and embryo transfer) and chi-square (for non-continuous data or percentage). The grade of relationship between continuous variables was calculated by Pearson's correlation coefficient (r) and the outcomes were considered statistically significant when $\mathrm{p}$ value was less than 0.05 .

\section{Results}

A total number of 45 infertile women were nominated in this cross-sectional comparative study, 23 patients were diagnosed with polycystic ovary syndrome (PCOS group) and 22 patients without polycystic ovary syndrome (non-PCOS group), as shown in Figure 1.

\subsection{Comparison of Mean Age and BMI Between PCOS and non- PCOS Patients}

The comparison of mean patients age and Body Mass Index (BMI) between PCOS and nonPCOS patients were presented in Table 1 . The results expressed as mean \pm standard deviation. There was a significant difference in BMI ( $p=0.01)$ between the two groups with higher BMI in PCOS patients, nevertheless there was no significant difference in mean patients age $(\mathrm{p}=0.213)$ between PCOS and non PCOS patients.

\subsection{Comparison of Hormonal Levels Between PCOS and non-PCOS Groups}

The comparison of hormonal levels between PCOS and non-PCOS groups were established in Table 2. There were significant differences between the two groups about Antimullerian Hormone $(\mathrm{AMH})(\mathrm{p}=0.008)$ and $\mathrm{E} 2$ at day of trigger $(\mathrm{p}=0.012)$ with higher levels in PCOS group, but there was no significant difference in Follicle Stimulating Hormone (FSH), Luteinizing Hormone (LH) and basal Estradiol (E2) levels between PCOS and non-PCOS groups $(\mathrm{p}>0.05)$.

\subsection{Comparison of Pregnancy- Associated Plasma Protein Between PCOS and non-PCOS Patients}

In the current study, at the day of oocytes pickup and at the time of embryo transfer, we 
measured serum and follicular fluid (PAPP-A) levels, according to the results there were higher serum and follicular fluid (PAPP-A) levels in non-PCOS patients without statistically significant difference between PCOS and non PCOS groups ( $p>0.05)$, as shown in Table 3.

\subsection{Relationships Between Serum and Follicular PAPP-A Levels with Oocytes and Embryo Characteristics}

The relationships between serum PAPP-A levels with patients' oocytes characteristics, and embryos characteristics were shown in Table 4 and Table 5 and the results also revealed no significant correlations between PAPP-A levels with all parameters (low Pearson's correlation coefficient and $\mathrm{p}>0.05$ ).

\subsection{Comparison of Pregnancy- Associated Plasma Protein A (PAPP-A) Levels Between Pregnant and non-Pregnant Patients}

The comparison of serum PAPP-A levels between pregnant and non-pregnant patients was presented in Table 6, as a result there was higher serum and follicular fluid PAPP-A levels in women with positive pregnancy but without significant differences between pregnant and non-pregnant $(\mathrm{p}>0.05)$.

\section{Discussion}

In the present study, there was no significant difference in mean patient age $(p=0.213)$ between PCOS and non-PCOS patients. While the BMI was higher in PCOS patients and significant difference $(\mathrm{p}=0.01)$ between PCOS and non-PCOS patients, Furthermore, the statistical analysis of basal hormonal profile level in this research (FSH, LH, and E2) showed no significant differences $(\mathrm{P}>0.05)$ between the studied groups. On the other hand, the granulosa cells that surround parenteral and antral follicles produce $\mathrm{AMH}$, which plays a crucial role in follicle growth and maturation. AMH serum levels have been proposed as a marker for PCOS in several investigations (Bako, et al. ${ }^{[9]}$ ). The current study presented a significant difference in AMH levels $(\mathrm{p}=0.008)$ between the PCOS and non-PCOS groups at the day of trigger, with higher levels in the PCOS group. 


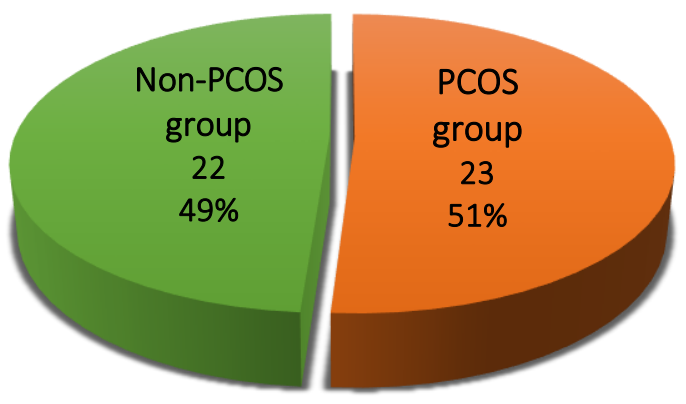

Figure (1): Comparison of demographic features between PCOS and non-PCOS patients

Table (1): Comparison of Age and BMI between PCOS and non-PCOS group

\begin{tabular}{|c|c|c|c|}
\hline Parameters & $\begin{array}{c}\text { PCOS patients } \\
(\mathbf{n = 2 3 )}\end{array}$ & $\begin{array}{c}\text { Non-PCOS patients } \\
(\mathbf{n = 2 2})\end{array}$ & p-value \\
\hline $\begin{array}{c}\text { Age (years) } \\
(\text { Mean } \pm \text { SD) }\end{array}$ & $33.3 \pm 4.95$ & $34.4 \pm 5.5$ & 0.213 \\
\hline $\begin{array}{c}\left.\text { BMI (Kg/m } \mathbf{m}^{2}\right) \\
(\text { Mean } \pm \text { SD) }\end{array}$ & $28.16 \pm 3.1$ & $25.25 \pm 4.06$ & $0.010^{*}$ \\
\hline
\end{tabular}

$*$ : p value $<0.05$ (significant)

Table (2): Comparison of hormonal levels between PCOS and non-PCOS groups

\begin{tabular}{|c|c|c|c|}
\hline Hormone & $\begin{array}{c}\text { PCOS group } \\
(\text { Mean } \pm \text { SD) }\end{array}$ & $\begin{array}{c}\text { non-PCOS group } \\
(\text { Mean } \pm \text { SD })\end{array}$ & p-value \\
\hline FSH $(\mathbf{m I U} / \mathbf{m l})$ & $6.11 \pm 1.99$ & $6.4 \pm 1.84$ & 0.663 \\
\hline $\mathbf{L H}(\mathbf{m I U} / \mathbf{m l})$ & $7.68 \pm 6.79$ & $4.8 \pm 2.29$ & 0.097 \\
\hline $\mathbf{A M H}(\mathbf{n g} / \mathbf{m l})$ & $3.02 \pm 2.2$ & $1.39 \pm 0.86$ & $0.008^{*}$ \\
\hline $\mathbf{E}_{\mathbf{2}}(\mathbf{p g} / \mathbf{m l})$ & $59.3 \pm 26.9$ & $55.78 \pm 45.97$ & 0.826 \\
\hline $\begin{array}{c}\mathbf{E}_{2} \text { at trigger } \\
\text { time }(\mathbf{p g} / \mathbf{m l})\end{array}$ & $1661 \pm 1112$ & $733 \pm 626$ & $0.012^{*}$ \\
\hline
\end{tabular}

SD: Standard deviation; *: $p$-value $<0.05$ (significant). 
Table (3): Comparison of PAPP-A levels between PCOS and non-PCOS patient

\begin{tabular}{|c|c|c|c|}
\hline PAPP-A level (ng/ml) & $\begin{array}{c}\text { PCOS group } \\
(\text { Mean } \pm \text { SD) }\end{array}$ & $\begin{array}{c}\text { non-PCOS group } \\
\text { (Mean } \pm \text { SD) }\end{array}$ & p-value \\
\hline $\begin{array}{c}\text { Serum PAPP-A levels at } \\
\text { day of oocytes pickup }\end{array}$ & $4.02 \pm 3.73$ & $7.96 \pm 5.84$ & 0.079 \\
\hline $\begin{array}{c}\text { Serum PAPP-A levels at } \\
\text { day of embryo transfer }\end{array}$ & $14.48 \pm 6.52$ & $16.46 \pm 9.63$ & 0.171 \\
\hline $\begin{array}{c}\text { Follicular fluid PAPP-A } \\
\text { levels }\end{array}$ & $1.55 \pm 1.18$ & $1.59 \pm 0.90$ & 0.916 \\
\hline
\end{tabular}

Table (4): Relationships between PAPP-A Levels in serum and follicular fluid with Oocyte characteristic

\begin{tabular}{|c|c|c|c|c|}
\hline \multicolumn{2}{|c|}{ Parameters } & $\begin{array}{l}\text { PAPP-A level in } \\
\text { serum at oocytes } \\
\text { pickup day }\end{array}$ & $\begin{array}{l}\text { PAPP-A level } \\
\text { in serum at } \\
\text { ET day }\end{array}$ & $\begin{array}{c}\text { Follicular } \\
\text { fluid PAPP-A } \\
\text { level }\end{array}$ \\
\hline \multirow{2}{*}{$\begin{array}{l}\text { Total oocytes } \\
\text { count }\end{array}$} & $\boldsymbol{R}$ & -0.112 & 0.015 & -0.037 \\
\hline & p-value & 0.461 & 0.922 & 0.811 \\
\hline \multirow{2}{*}{ MI } & $R$ & -0.087 & 0.017 & -0.149 \\
\hline & $p$-value & 0.575 & 0.911 & 0.334 \\
\hline \multirow{2}{*}{ MI } & $R$ & -0.133 & 0.056 & 0.053 \\
\hline & $p$-value & 0.389 & 0.719 & 0.727 \\
\hline \multirow{2}{*}{ GV } & $R$ & -0.059 & -0.055 & -0.243 \\
\hline & p-value & 0.706 & 0.729 & 0.113 \\
\hline \multirow{2}{*}{$\begin{array}{l}\text { Abnormal } \\
\text { oocytes }\end{array}$} & $R$ & -0.049 & -0.130 & -0.058 \\
\hline & $p$-value & 0.753 & 0.398 & 0.709 \\
\hline \multirow{2}{*}{$\begin{array}{l}\text { Maturity } \\
\text { index }\end{array}$} & $R$ & 0.038 & 0.009 & -0.017 \\
\hline & p-value & 0.803 & 0.952 & 0.914 \\
\hline
\end{tabular}


Table (5): Correlations between PAPP-A Levels in serum and follicular fluid with embryo characteristic

\begin{tabular}{|c|c|c|c|c|}
\hline \multirow{2}{*}{ Parameters } & \multicolumn{2}{|c|}{$\begin{array}{c}\text { PAPP-A level in serum } \\
\text { at oocytes pickup day }\end{array}$} & $\begin{array}{c}\text { PAPP-A level } \\
\text { in serum at ET } \\
\text { day }\end{array}$ & $\begin{array}{c}\text { Follicular } \\
\text { fluid PAPP- } \\
\text { A level }\end{array}$ \\
\hline \multirow{2}{*}{$\begin{array}{c}\text { Total embryo } \\
\text { count }\end{array}$} & $\boldsymbol{R}$ & 0.222 & 0.049 & 0.002 \\
\cline { 2 - 5 } & $\boldsymbol{p}$-value & 0.146 & 0.755 & 0.985 \\
\hline \multirow{2}{*}{ G I } & $\boldsymbol{R}$ & 0.232 & -0.038 & 0.026 \\
\cline { 2 - 5 } & $\boldsymbol{p}$-value & 0.128 & 0.806 & 0.866 \\
\hline \multirow{2}{*}{ GII } & $\boldsymbol{R}$ & -0.002 & 0.005 & 0.053 \\
\cline { 2 - 5 } & $\boldsymbol{p}$-value & 0.994 & 0.974 & 0.726 \\
\hline \multirow{2}{*}{ GIII } & $\boldsymbol{R}$ & -0.082 & -0.222 & 0.049 \\
\cline { 2 - 5 } & $\boldsymbol{p}$-value & 0.602 & 0.145 & 0.755 \\
\hline \multirow{2}{*}{$\begin{array}{c}\text { Fertilization } \\
\text { rate }\end{array}$} & $\boldsymbol{R}$ & 0.189 & 0.109 & 0.051 \\
\cline { 2 - 5 } & $\boldsymbol{p}$-value & 0.243 & 0.483 & 0.748 \\
\hline
\end{tabular}

R: Pearson`s correlation coefficient

Table (6): Comparison of PAPP-A levels between pregnant and non-pregnant patients

\begin{tabular}{|c|c|c|c|}
\hline $\begin{array}{c}\text { PAPP-A level } \\
(\mathbf{n g} / \mathbf{m l})\end{array}$ & $\begin{array}{c}\text { Positive } \\
\text { pregnancy } \\
(\mathbf{n}=\mathbf{1 7})\end{array}$ & $\begin{array}{c}\text { Negative } \\
\text { pregnancy } \\
(\mathbf{n = 2 8})\end{array}$ & P-value \\
\hline $\begin{array}{c}\text { Serum PAPP-A levels at } \\
\text { day of oocyte pickup }\end{array}$ & $6.83 \pm 10.85$ & $5.62 \pm 4.86$ & 0.619 \\
\hline $\begin{array}{c}\text { Serum PAPP-A levels at } \\
\text { day of embryo transfer }\end{array}$ & $14.88 \pm 12.81$ & $14.67 \pm 10.47$ & 0.968 \\
\hline $\begin{array}{c}\text { Follicular fluid PAPP-A } \\
\text { levels }\end{array}$ & $1.77 \pm 1.35$ & $1.49 \pm 0.83$ & 0.404 \\
\hline
\end{tabular}

$p$-value $<0.05$ (significant). 
Likewise, as (Wiweko, et al. ${ }^{[10]}$ ) proposed there were also statistically significant differences between the PCOS and non-PCOS patient in AMH levels. PAPP-A is a zincbinding metalloproteinase that shows an important role in the IGF pathway (Kiliç and Guiler ${ }^{[11]}$, Boldt et al., $\left.{ }^{[12]}\right)$. In this study, the level of PAPP-A was compared between the PCOS and non-PCOS groups, and the results presented that non-PCOS patients had higher serum and follicular fluid PAPP-A levels but without statistically significant differences ( $p$ $>0.05$ ). While (Wetta, et al. ${ }^{[13]}$ ) showed that women with a PAPP-A value of less than 0.4 MoM were more expected to develop PCOS. Women with PCOS had a lower PAPP-A level than normal. However, there was no relation between infertility and PAPP-A levels that are less than 0.4 MoM. Although (Öztürk, et al. ${ }^{[8]}$ ) showed that the patients with PCOS revealed higher PAPP-A levels than healthy women, other studies suggested that PAPP-A levels increase throughout a normal pregnancy. There is a sharp increase of about 24-fold between the end of the first trimester and the end of the second trimester, followed by a slower, 2-fold increase from the end of the second trimester up to delivery (Leguy, et al. $\left.{ }^{[14]}\right)$. These results reveal that the PAPP-A level increases in pregnant more than in nonpregnant women, mainly in the first trimester. Furthermore, in the current study, the relationships between serum and follicular fluid PAPP-A levels with patient oocyte characteristics and embryo characteristics, maturity index, and fertilization rate at days of pick-up and embryo transfer presented no significant correlations between PAPP-A levels with all parameters (low Pearson's correlation coefficient and $\mathrm{p}>0.05)$. Other studies observed there was no significant correlation between PAPP-A levels, fertilization and good quality embryos in two groups of women undergoing ART (Firouzabadi, et al. ${ }^{[15]}$ ). These statistics suggested that PAPP-A levels are responsible for the follicular maturity index but not for the oocyte quality and pregnancy potential. PAPPA levels in the blood start to increase soon after implantation and continue to increase during pregnancy, with a doubling period of 3-4 days during the first trimester and maximal levels at 
term, PAPP-A looks to be the dominating IGFBP-4 proteinase in serum of pregnancy. (Kirkegaard, et al. [16] , Fialova and Malbohan ${ }^{[17]}$ ). Herein, we show higher PAPP-A levels in serum and follicular fluid in women with positive pregnancy but without significant differences between pregnant and non-pregnant $(\mathrm{p}>0.05)$.

\section{Conclusions}

From this study, it was concluded that the higher level of PAPP-A in serum and follicular fluid in women with positive pregnancy but without significant differences can be used as a marker in predicting pregnancy after ICSI cycles. Secondly, nonsignificant difference was noted between PCOS and non-PCOS groups with higher PAPP-A levels in serum and follicular fluid on both days of oocyte retrieval and embryo transfer. In addition, there is no correlation between PAPP-A and oocytes and embryo characteristics.

\section{Acknowledgment}

We would like to acknowledge Al Nahrain University, Baghdad, Iraq.

\section{Funding}

This work received no funding.

\section{Author Contribution}

Altimimi, ZS, performed the study, examined and reviewed results, and manuscript writing with the help and supervision of Jwad, MA, and Mohammed, AA.

\section{Conflict of Interest}

The authors declare no conflict of interest.

\section{Ethical Clearance}

The study was approved by the Ethical Approval Committee.

\section{References}

[1]Mongkolchaipak S. Standard Ovarian Stimulation Protocols and Their Outcomes. Development of In Vitro Maturation for Human Oocytes. Springer International Publishing; 2017;129-46. [Online article $\underline{\text { link] }}$

[2]Chen Y, Xu X, Wang Q, Zhang S, Jiang L, Zhang C, et al. Optimum oocyte retrieved and transfer strategy in young women with normal ovarian reserve undergoing a long 
treatment protocol: a retrospective cohort study. Journal of Assisted Reproduction and Genetics. Springer Science and Business Media LLC; 2015 Sep 17;32(10):1459-67. [Online article link]

[3] Deshpande P, Gupta A. Causes and prevalence of factors causing infertility in a public health facility. Journal of Human Reproductive Sciences. Medknow; 2019;12(4):287. [Online article link]

[4]Ecklund LC, Usadi RS. Endocrine and Reproductive Effects of Polycystic Ovarian Syndrome. Obstetrics and Gynecology Clinics of North America. Elsevier BV; 2015 Mar;42(1):55-65. [Online article link]

[5] Fauser BCJM, Tarlatzis BC, Rebar RW, Legro RS, Balen AH, Lobo R, et al. Consensus on women's health aspects of polycystic ovary syndrome (PCOS): the Amsterdam ESHRE/ASRM-Sponsored 3rd PCOS Consensus Workshop Group. Fertility and Sterility. Elsevier BV; 2012 Jan;97(1):28-38.e25. [Online article link]

[6] Oxvig C. The role of PAPP-A in the IGF system: location, location, location. Journal of Cell Communication and Signaling.
Springer Science and Business Media LLC; 2015 Jan 25;9(2):177-87. [Online article $\underline{\text { link] }}$

[7] Kwintkiewicz J, Giudice L. The Interplay of Insulin-Like Growth Factors, Gonadotropins, and Endocrine Disruptors in Ovarian Follicular Development and Function. Seminars in Reproductive Medicine. Georg Thieme Verlag KG; 2009 Jan;27(01):043-51. [Online article link]

[8] Öztürk M, Öktem M, Altinkaya SÖ, Öktem EÖ, Elbeg Ş, Erdem A, et al. Elevated PAPP-A levels in lean patients with polycystic ovary syndrome. Taiwanese Journal of Obstetrics and Gynecology. Elsevier BV; 2018 Jun;57(3):394-8. [Online article link]

[9]Bako AU, Morad S, Atiomo WA. Polycystic ovary syndrome: An overview. Reviews in Gynaecological Practice. Elsevier BV; 2005 Jun;5(2):115-22. [Online article link]

[10] Wiweko B, Maidarti M, Priangga MD, Shafira N, Fernando D, Sumapraja K, et al. Anti-mullerian hormone as a diagnostic and prognostic tool for PCOS patients. Journal of Assisted Reproduction and Genetics. 
Springer Science and Business Media LLC; 2014 Aug 14;31(10):1311-6. [Online article link]

[11] Kiliç D, Güler ÖT. Serum pregnancyassociated placental protein-a (PAPP-A) levels are increased in polycystic ovary syndrome (PCOS) in women with oligoanovulation. Journal of Surgery and Medicine. Journal of Surgery and Medicine; 2021 Jan 1;5(1):36-40. [Online article link] [12] Boldt HB, Overgaard MT, Laursen LS, Weyer K, Sottrup-Jensen L, Oxvig C. Mutational analysis of the proteolytic domain of pregnancy-associated plasma protein-A (PAPP-A): classification as a metzincin. Biochemical Journal. Portland Press Ltd.; 2001 Aug 24;358(2):359-67. [Online article link]

[13] Wetta L, Mancuso M, Sutton A, Pekarek D, Cliver S, Biggio J. 727: Association between polcystic ovarian syndrome (PCOS) and first trimester pregnancy associated plasma protein-a (PAPP-A). American Journal of Obstetrics and Gynecology. Elsevier BV; 2011 Jan;204(1):S286. [Online article link]
[14] Leguy MC, Brun S, Pidoux G, Salhi H, Choiset A, Menet MC, et al. Pattern of secretion of pregnancy-associated plasma protein-A (PAPP-A) during pregnancies complicated by fetal aneuploidy, in vivo and in vitro. Reproductive Biology and Endocrinology. Springer Science and Business Media LLC; 2014 Dec;12(1). [Online article link]

[15] Dehghani Firouzabadi R, Mohammadian F, Mashayekhy M, Davar R, Eftekhar M. The correlation between follicular fluid pregnancy-associated plasma protein A levels, fertilization, and embryo quality in GnRH agonist and $\mathrm{GnRH}$ antagonist protocols in ART cycles. Iranian journal of reproductive medicine. 2012 Sep;10(5):477-82. [Online article link]

[16] Kirkegaard I, Uldbjerg N, Oxvig C. Biology of pregnancy-associated plasma protein-A in relation to prenatal diagnostics: an overview. Acta Obstetricia et Gynecologica Scandinavica. Wiley; 2010 Sep;89(9):1118-25. [Online article link]

[17] Fialova L, Malbohan IM. Pregnancyassociated plasma protein A (PAPP-A): 
theoretical and clinical aspects. Bratislavske lekarske listy, 2002;103(6):194-205. [Online article link]

\section{Peer Review Information}

Double-Blind Peer Review in which both authors and reviewers does not know each other.

This work was reviewed by

Asst. Prof. Dr. Jabbar Al-Hilfy

Asst. Prof. Dr. Lubna Amer Al-Anbari

Editorial Policy

The editorial policy at IJEIR ensured that

this article fit the standards of scientific publications.

This work was copyedited by

$\underline{\text { Dr. Taif Alawsi }}$

\section{Authors Biographies}

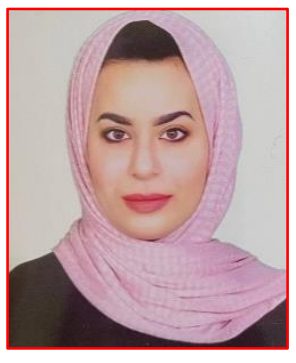

\section{Zeena Salim Altimimi}

She received her B.Sc. in veterinary medicine and surgery from the University of Baghdad in 2013, and her M.Sc. in applied embryology in 2021 from the High Institute of Infertility Diagnosis and Assisted Reproductive Technologies, Al Nahrain University, Baghdad, Iraq.

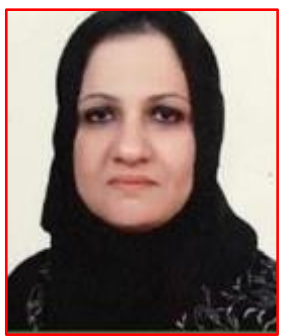

Dr. Mufeda Ali Jwad

She received her MBChB. From the College of Medicine at the University of Baghdad in 1996. Her M.Sc. in Applied Embryology and her Ph.D. in Infertility and Clinical Reproduction were from the High Institute of Infertility Diagnosis and Assisted Reproductive Technologies, Al Nahrain University in 2007 and 2018 respectively. She worked as a rotator in the Baghdad health department from 1996-1999. She worked in Gyn. \& Obs. in Alsamawa general hospital and Babylon hospital from 2000-2003. She worked at the Babylon University, College of Medicine, anatomy and embryology department from 2003-2004. She has been working as a specialist physician and a consultant clinic at the High Institute of Infertility Diagnosis and Assisted Reproductive Technologies, Al Nahrain University from 2008-2015. Currently, she is an assistant professor and specialist in infertility and clinical reproduction. She is the head of the clinical reproductive physiology department from 2019 till now. She has more than 25 published articles in national and international journals.

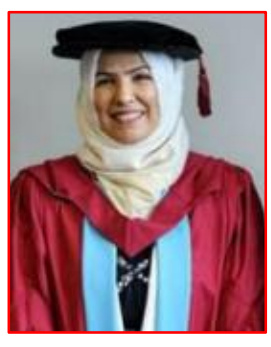

\section{Dr. Amal A. Mohammed}

She works at the High Institute of Infertility Diagnosis and Assisted Reproductive Technologies, Al Nahrain University, Baghdad, Iraq. 


\section{(C) (i) 2021 Author(s)}

This article is licensed under a Creative Commons Attribution 4.0 International License, which permits use, sharing, adaptation, distribution and reproduction in any medium or format, as long as you give appropriate credit to the original author(s) and the source, provide a link to the Creative Commons license, and indicate if changes were made.

http://creativecommons.org/licenses/by/4.0/. 